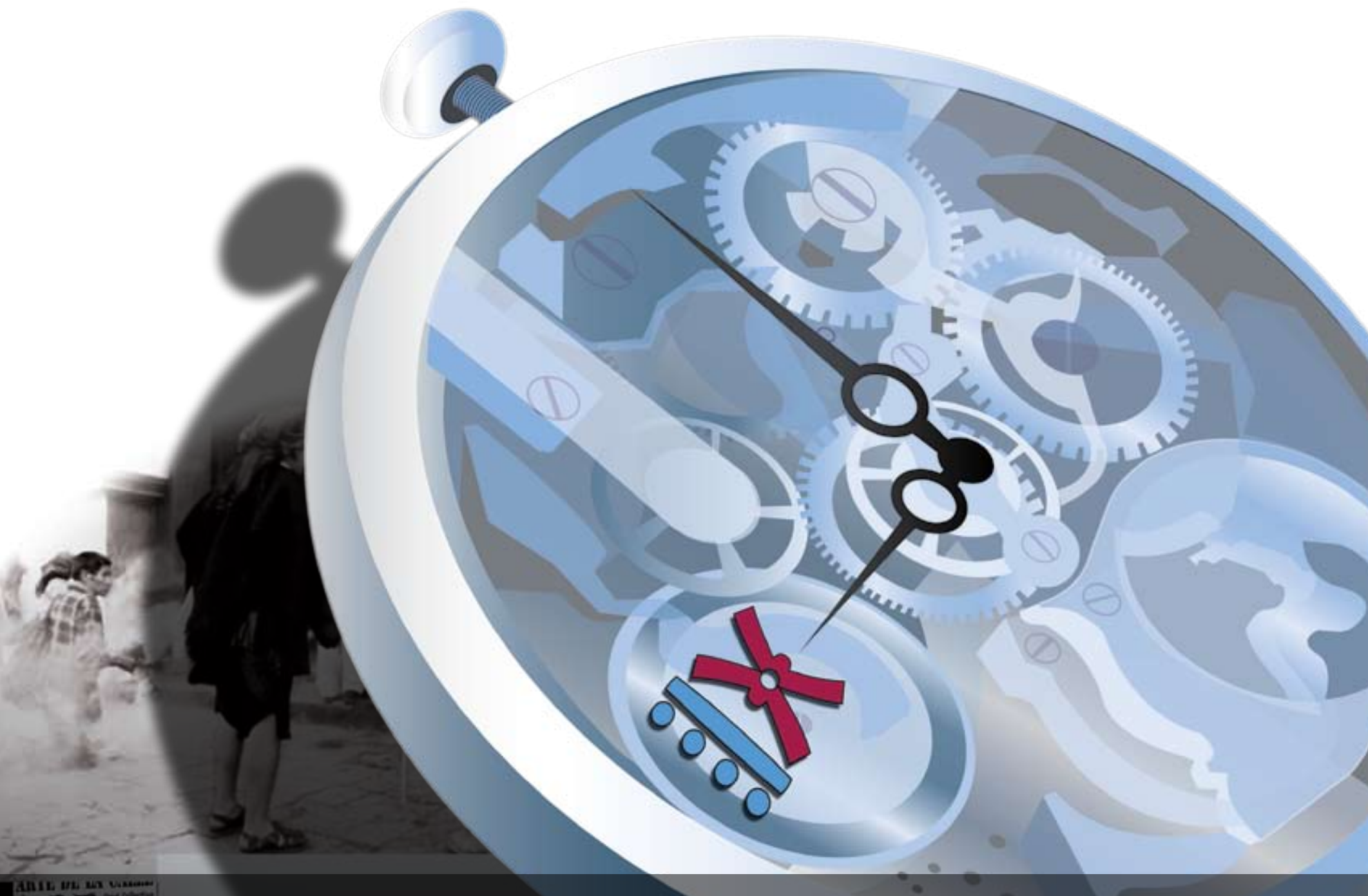

$9^{\circ}$ C O N G R ES O 2. CENTROAMERICANO DE H ISTO R I A

Universidad de Costa Rica ISSN 1409- 469X

Fecha de recepción: 15 de mayo 2008 Fecha de aceptación: 30 de mayo 2008

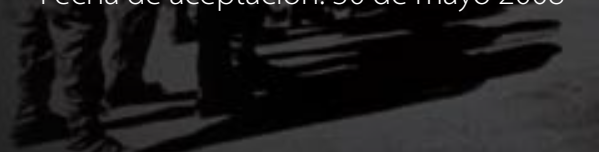

El corrido revolucionario como fuente para la historia de la mujer en armas: Guatemala

Miembros del Consejo Editorial:

Dr. Ronny Viales, Dr. Juan José Marín

Editores Técnicos:

Allan Fonseca, Andrés Cruz, Gabriela Soto
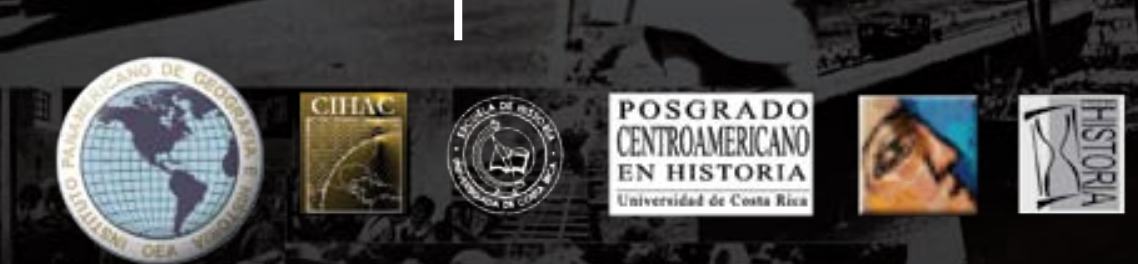
Indexaciones: Repositorio de Revistas UCR, DIALNET, Latindex, REDALYC Directorio y recolector de recursos digitales del Ministerio de Cultura de España, Directory of Open Access Journals. Diálogos Revista Electrónica de Historia ISSN 1409-469X. Número especial 2008. Dirección web: http://historia.fcs.ucr.ac.cr/dialogos.htm

\title{
El corrido revolucionario como fuente para la historia de la mujer en armas: Guatemala $^{1}$
}

\author{
Dr. José Domingo Carrillo
}

Coordinación de Ciencias Sociales y Humanidades Universidad Autónoma de San Luis Potosí, México

1 Esta ponencia se originó en las propuestas que hicieron los estudiantes de antropología del semestre agosto-diciembre 2007 en la UASLP 
El objetivo de ésta ponencia es valorar al corrido como fuente para conocer el papel desempeñado por las mujeres en los movimientos armados guatemaltecos. A través del análisis de las letras de los corridos recopilados y publicados se puede apreciar el lugar que ocuparon las mujeres en las filas de los movimientos armados, a saber, la mujer trofeo, la mujer combatiente, la mujer amante y la mujer madre. Estas y otras funciones fueron empleadas para representar la figura femenina y divulgar las noticias de las acciones realizadas por los movimientos armados guatemaltecos que incluyeron en sus filas a mayas y ladinas. ${ }^{2}$

La ponencia se divide en dos apartados; en el primero se realiza una caracterización del corrido como género musical y el segundo, se ocupa del análisis de la letra de algunos corridos para examinar sus ventajas y limitaciones como fuente para la investigación de la mujer en la historia reciente de Guatemala.

No obstante proliferar en Guatemala el gusto por la música llamada revolucionaria, es interesante subrayar que este género musical escrito por los combatientes durante los años de la guerra interna no es interpretado actualmente, a diferencia de los narcocorridos o las letras de autores latinoamericanos cuya difusión goza de mayor alcance en Guatemala. ${ }^{3}$ Esto puede apreciarse leyendo las reacciones que motivó la reciente visita de Mercedes Sosa a Guatemala en las cuales se opina cuáles son la ventajas de la música latinoamericana pero que desconoce la producción 2 Arriola, Aura Marina, Ese obstinado sobrevivir. Auto etnografía de una mujer guatemalteca, Guatemala, Ediciones del Pensativo, 2000; Camey, Carmen, El despegue -Relato testimonial-, Guatemala, URNG, 2001; Colom, Yolanda, Mujeres en la alborada. Guerrilla y participación femenina en Guatemala. 1973-1978, Guatemala, Editorial Artemis Edinter, 2000; Ramírez, Chiqui, La guerra de 36 años vista con ojos de mujer de izquierda, Editorial Oscar de León Palacios, Guatemala, 2001; Reyna Caba, Engracia, Kal Bóp Relato testimonial, Guatemala, URNG, 2001.

3 Los especialistas en el tema de la música no incluyen en sus estudios ni una sola referencia al género que nos ocupa, las contribuciones provienen más bien de la antropología. Véase por ejemplo Cultura de Guatemala, Guatemala, Universidad Rafael Landívar, año XXI, Vol. III, Septiembre-Diciembre 2000, Anuario Musical 2000 
musical de las guerrillas guatemaltecas. ${ }^{4}$

\section{El corrido y sus definiciones}

El Diccionario de la Real Academia de la Lengua Española define al corrido como un romance cantado, propio de Andalucía y agrega que es una composición octosilábica con variedad de asonancias, que puede bailarse y acompañarse con la guitarra al son del fandango. ${ }^{5}$ En México el corrido es considerado como

Un género épico-lírico-narrativo, en cuartetas de rima variable, ya asonante o consonante de los versos pares, forma literaria sobre la que se apoya una frase musical compuesta generalmente de cuatro miembros, que relata aquellos sucesos que hieren poderosamente la sensibilidad de las multitudes; por lo que tiene épico deriva del romance castellano y mantiene normalmente la forma general de éste conservando su carácter narrativo de hazañas guerreras y combates, creando entonces una historia por y para el pueblo. ${ }^{6}$

De igual forma Navarrete señala que las adaptaciones del romance español en América produjeron un resultado específico de Latinoamérica,

El pueblo ignora su origen remoto y, al transmitirlo oralmente, identifica en las letras acontecimientos, alegrías y esperanzas de un mundo cercano e íntimo. De ese tomar incorporando, suprimiendo lo incomprensible para intercalar lo propio nació una forma netamente americana: el corrido. ${ }^{7}$

$4 \quad$ Velásquez Carrera, Eduardo Antonio, "Mercedes Sosa: los recuerdos que trae," en www. elperiodico..com.gt. Consultado el 5 de febrero de 2008.

5 Diccionario esencial de la lengua española. Madrid, Espasa Calpe, 2006, p. 417

6 Mendoza, Vicente T., El corrido mexicano, México, FCE, 2003, p. IX

7 Navarrete, Carlos, El romance tradicional y el corrido en Guatemala, México, Universidad Nacional Autónoma de México, 1987, p. 77 
El corrido hunde sus raíces en la tradición y en el ingenio de los grupos subalternos, en las vivencias y en las relaciones sociales debido a que son recurrentes los nombres de personas, lugares y fechas que relatan el martirio de hombres y caudillos, ${ }^{8}$ el corrido podría considerarse como el cancionero popular de un pueblo puesto que son narrativas de la historia y recreación de la realidad social, son una manera más, al igual que la literatura popular, que muestra a través del folclore la tragedia de la guerra porque tal y como lo señala Gombrich la imaginación contenida en los testimonios orales y escritos es un reordenamiento de la realidad para alterar la apariencia de lo acontecido ${ }^{9}$ condición que el corrido admite puesto que es capaz de transfigurar lo trágico y lo desagradable en un desafío a la estética. ${ }^{10}$ El folclore, como lo señala Thompson le otorga a la disciplina histórica la posibilidad de ubicar los significados de la cultura popular en un contexto y en esta ponencia el corrido revolucionario es ubicado en el contexto de la guerra interna y en uno más, en el olvido en el que ha caído: como fuente de investigación y como género musical poco apreciado por los llamados cantautores guatemaltecos contemporáneos. ${ }^{11}$

No obstante, Guatemala durante el siglo XX ha sido testigo de todo tipo de movimientos sociales, desde las luchas contra las dictaduras -caída de Manuel Estrada Cabrera (1890-1920) y Jorge Ubico (1932-1994)- hasta movimientos de distinto tipo ideológico como el derrocamiento de Jacobo 8 Chapela Bojórquez, Tiosha, De narcos y ganstas: similitudes y diferencias discursivas en torno a la figura del narcotraficante en el narcocorrido y el gansta rap, en Olmos Aguilera, coordinador, Antropología de las fronteras. Alteridad, historia e identidad más allá de la línea, México, El Colegio de la Frontera Norte, Miguel Ángel Porrúa, p. 124. véase la recopilación de corridos de la revolución mexicana en Avitia Hernández, Antonio, Corrido histórico mexicano. Voy a cantarles la historia (196-1924), México, Edit. Porrúa, 1997, Tomo III.

$9 \quad$ Gombrich, E. H., Historia del arte, Phaidon Press Limited, 2007, p. 27

10 Gombrich, E.H., Ideales e ídolos. Ensayos sobre los valores en la historia y el arte. Madrid, Editorial Debate, 1999, p. 190.

11 Thomposn, E. P., Agenda para una historia radical, Barcelona, Editorial Crítica, 2000, pp. 15-43 
Arbenz Guzmán (1950-1954) pasando por movimientos nacionalistas como el levantamiento militar del 13 de Noviembre de 1960 que conduciría a la formación de los movimientos armados de corte marxista e indigenistas. ${ }^{12}$ De todos estos episodios que forman parte de la historia nacional la sociedad guatemalteca ha dejado testimonios orales, escritos, hemerográficos, fotográficos o musicales; de estos últimos forman parte los corridos revolucionarios escritos por manos anónimas - puesto que los autores los firman con seudónimo- que dan cuenta de la vorágine del costo social que tuvo la guerra para el país.

El valor historiográfico del corrido, como lo señala Alicia Olivera es que forma parte de los documentos personales que aporta datos fidedignos, de nombres ignorados que la historia no menciona pero que realizaron acciones importantes o hicieron gala de valor, o bien identifica a villanos o traidores que deberían odiarse. También fueron crónica de combates importantes sin lo cuales no podríamos reconstruir las diferentes etapas de la guerra y de los movimientos armados contemporáneos pero todos ellos forman parte de la historia del país. ${ }^{13}$

El corrido revolucionario guatemaltecos es como lo define Locatelli, el tipo de música protesta que pregona la revolución e incita al pueblo a la lucha y para el músico revolucionario es esta la consecuente y válida. ${ }^{14}$ La música, tanto instrumental como a capella acompañó a los destacamentos de hombres armados que dieron origen a las fuerzas rebeldes que durante los años 1960-1996 se plantearon transformar a Guatemala. Mario Payeras relata que durante los años de organización e implantación del Ejército Guerrillero de los Pobres (EGP) en la selva del Ixcán en los inicios de la década de los años setenta, durante los descansos entonaban canciones aun 12 Payeras, Mario, Los fusiles de octubre. Ensayos y artículos militares sobre la revolución guatemalteca 1985-1988, México, Juan Pablos Editor, 1991, pp.199-200

13 Fonoteca del INAH, Corridos de la revolución cristera, México, Instituto Nacional de Antropología e Historia-CONACULTA, 2002, No. 20

14 Locatelli de Pérgamo, Ana María, "Raíces musicales", en Aretz, Isabel, América Latina en su música, México, Editorial Siglo XXI, 1993, p. 69 
y cuando desconocieran algunas estrofas $; Y$ en ese Atotonilco de naranjos en flor parecen las muchachas angelitos de Dios son más lindas que una canción de esas que son puro amor!...Son tus mujeres hermosas como capullos de rosas... ${ }^{15}$

El testimonio de Santiago Santa Cruz de igual forma señala que Llegamos a tener un himno del Frente, a cuya letra le puso como fondo musical la canción "Submarino amarillo" de los Beatles. La posesión de radios de frecuencia modulada o de onda corta sirvió para escuchar música y como señala el autor era el que nos vinculaba con la realidad. ${ }^{16}$

La música y el corrido en particular fueron expresiones de las formas de pensar de los rebeldes guatemaltecos, reflejan una realidad que complementándola con otro tipo de información provee al investigador avezado los significados afectivos, utópicos, de violencia, de estatus y otros que se advierten en las letras de los corridos y que le asignan los autores a la reconstrucción social de la realidad que hicieron los rebeldes alzados en armas. De esa cuenta los corridos pueden ser considerados como una fuente más para el estudio de las guerrillas guatemaltecas que reflejan las aspiraciones individuales y colectivas de los insurgentes.

\section{La música de las armas}

Los corridos incluyen un título que da nombre a la letra y que hace referencia al tema, como por ejemplo el corrido intitulado La mujer guerrillera que hace alusión a la entrega de la mujer a la causa revolucionara; una presentación que puede abordar aspectos que incluyen descripciones de la fauna, de la flora, o de combates realizados como el Corrido del 12 de abril del año 84: “Compañeros queridos que están en nuestra lucha aquí les vamos a cantar una historia del combate que fue allá en San Lucas del departamento del Quiché, en donde nuestro queridos combatientes hicieron a retumbar la carretera."

15 Payeras, Mario, Los días de la selva, Guatemala, Editorial Piedra Santa, 1998, p. 63

16 Santa Cruz Mendoza, Santiago, Insurgentes. Guatemala, la paz arrancada, Santiago de Chile, Ediciones LOM, 2004, pp. 59,70 y 98 
El corrido incluye el desarrollo que narra la temática a la cual se refiere como en el titulado Ese niño "Todos los días temprano se levanta a trabajar es un niño y es un hombre porque lo explotan también." Y una conclusión que puede asumir una moraleja o una reflexión como la siguiente estrofa final del mismo corrido "Y cuando todos los niños se levante contra el hambre aunque nos cueste la sangre conquistaremos la paz aunque nos cueste sangre conquistaremos la paz." Para los propósitos de esta ponencia interesa destacar la denominación de las mujeres que ocuparon papeles de amantes, como en el corrido La mamita firmado por Ernesto, en el cual se advierte el cortejo hacia una indígena mam "Ya la lucha del pueblo avanza con vos, conmigo y con los demás no seas malita mamita apurate decime que sí." Las mujeres oprimidas como en el corrido La tortillera "Y cuando el sol te da de frente suda tu piel tostada y al final de la jornada te resientes de cansada"; las mujeres combatientes como en el corrido La Juanita cuyo autor es un militante del Partido Guatemalteco del Trabajo (PGT) y la letra esta dedicada a la compañera Lía "Fue una linda madrugada, que ella sola se marchó, por amar tanto a su pueblo, a la montaña se asomó."

Un análisis más detenido debe subrayar que son las percepciones que reflejan la realidad según el autor tal y como las vivió y cómo las siente de la sociedad que describe y del auditorio, este último generalmente compuesto por la tropa combatiente.

Los corridos empleados para escribir esta ponencia fueron tomados de una grabación que me obsequió durante la realización de mi trabajo de campo el ex combatiente del Ejército Guerrillero de los Pobres (EGP) Joaquín Ávila Tum quien residía en la colonia 29 de Diciembre localizada en el municipio de Zaragoza departamento de Chimaltenango. La versión estenográfica se completó con la edición de corridos revolucionarios publicados por el EGP. ${ }^{17}$

En el siguiente corrido se mezclan versos de distinta extensión y esta dedicado a una mujer 17 EGP, Cancionero histórico del EGP, Sin lugar de edición, s.f. 142 pp. 
llamada Juanita a quien se le compara con la delicadeza de la flor, también se advierte que el rostro del personaje femenino esta encarnado por la revolución "Ella es una tierna flor, en su rostro solo lleva encarnar a la revolución. Que rechula morenita y se llama la Juanita, cariñosamente yo la llamo mi capullina de amor."

En las siguientes estrofas se advierte el discurso ejemplar cuando en la letra del corrido el autor escribe sobre la transformación de la mujer en combatiente "Cuando escuchar, es un deber, en combatiente se convierte la mujer; cuando se da el corazón, cuando la entrega se convierte en un fusil, de que los hombres no se rinden de la explotación. Así es mi hermana militante y guerrillera cada día y cada hora su fusil a de alzar."

En la siguiente estrofa se advierte la hermandad creada en el fragor de la guerra en la cual las diferencias por género se borraban debido a que en igualdad de condiciones se enfrentaba la posibilidad de caer en combate o ser capturados por el ejército nacional, “Así es mi hermana militante y guerrillera cada día y cada hora su fusil a de alzar. Compañera en la trinchera, una sonrisa debes llevar, compañera tu verde olivo, siempre presente debes tener."

Silvia Soriano señala que la importancia de correlacionar mujeres y guerra tiene como propósito esclarecer si la guerra es capaz por sí misma de modificar las relaciones de género y si esta modificación es de fondo o coyuntural. Si bien, señala la autora, la guerra es declarada y dirigida por hombres, es preciso indagar los motivos de las mujeres por incorporarse al conflicto y añade Soriano Hernández que sí bien compartieron las mismas habilidades castrenses no fue ese el fin principal que explicaría la integración de las mujeres en los movimientos armados. ${ }^{18}$

He señalado en otro lugar que la incorporación de las mujeres dependió de su origen económico, social y étnico, y que estas variables no solamente deben relacionarse con la guerra, también

18 Soriano Hernández, Silvia, Mujeres y guerra en Guatemala y Chiapas, México, Universidad Nacional Autónoma de México, 2006, pp.21-22 
debe hacerse en función de las jerarquías sociales creadas en el seno de los movimientos armados y contemplar como funcionaron al interior de las propias mujeres. Esto responde a las interrogantes propuestas por Soriano y permite observar como los mismos movimientos armados reprodujeron en su seno las desigualdades sociales que caracterizaron y caracterizan a la sociedad guatemalteca. ${ }^{19}$

Si bien la letra de los corridos citan en igualdad de condiciones a mujeres y hombres para integrarse a la lucha armada, fue usual que las mujeres ocuparon los escalones inferiores en la estructura interna de las organizaciones armadas, en la siguiente estrofa se llama al alzamiento armado sin ningún tipo de distinción: "Hombres y mujeres vamos todos a pelear a incorporarnos a las milicias, de nuestra patria, que tanto lo merece."

Sin embargo, y a pesar de los esfuerzos pregonados por hacer de las organizaciones armadas espacios incluyentes de representación social, estas fueron al cabo del tiempo un espejo de la sociedad guatemalteca puesto que en el seno de los movimientos armados la desigualdad social, la diferenciación étnica y la subordinación de género fueron variables que significaron un obstáculo interno que las mismas organizaciones armadas fueron incapaces de resolver.

Las armas y su música son al cabo de tiempo un recuerdo, vestigios de la historia inmediata que desde la música popular ha caído en desuso debido a que los corridos no forman parte del repertorio de los llamados cantautores contemporáneos y desde la disciplina histórica no ha sido valorados como parte de la cultura popular musical de Guatemala. ${ }^{20}$

\section{Conclusiones}

19 Carrillo, José Domingo, "Pensar la guerra desde la historia: mujeres y guerrilla en Guatemala, 1960-1996," en Rubio, María Amalia, Rompiendo diques. Hacia una construcción de la equidad de género, México, Universidad Autónoma de Aguascalientes, 2006, pp. 231-251 20 Cultura de Guatemala, Anuario Musical 2000, Guatemala, Universidad Rafael Landívar, Septiembre-Diciembre, 2000, Año XXI, Vol. III, 120 pp. 
Los corridos como fuente de investigación admiten conocer la manera en que fue representada la mujer que se alzó en armas durante los años de la guerra en Guatemala. Tal y como afirma Hombsawm, los bandidos y los revolucionarios son mujeriegos y requieren expresar manifestaciones de virilidad ${ }^{21}$, ello explica que el papel más frecuente de las mujeres sea el de la mujer trofeo como amante, pero también se muestran mujeres hermanas, combatientes, madres, oprimidas. Todas estas presencias destacan el papel que desempeñaron las mujeres en las filas de los movimientos armados sin que por ello se modificara su posición subordinada debido a su condición de género. Esto se observa porque ninguna de las letras de los corridos, al menos en la edición impresa, aparece una mujer como autora. A pesar de esa condición marginal que se expresó en los distintos ámbitos de la vida militante, la presencia femenina se explica por la movilización social que caracterizó las décadas de los años sesenta y setentas en las cuales participaron las mujeres lo cual supuso cambios personales en tanto que se transgredieron las limitaciones que inhibían la participación femenina en la vida pública del país. Fue a través de las organizaciones armadas los sitios en los cuales los grupos tradicionalmente marginados como los indígenas y las mujeres pudieron crear espacios de representación social. El 29 de diciembre finalizó la guerra en Guatemala, la música de marimba amenizó los eventos oficiales y los corridos que relatan los años de la guerra esperan aún al trovador que los entone. El investigador familiarizado a la búsqueda de nuevas fuentes, confirma que después de la guerra lo que permanece es la música de las armas para conocer una parte de nuestro pasado.

21 Hobsbawm, Eric, Bandidos, Barcelona, Editorial Crítica, 2003, p. 157 